\title{
Mensagens sobre a Medicina de Família e Comunidade e a Atenção Primária à Saúde dirigida a Médicas e Médicos de Família e Comunidade, residentes, estudantes de Medicina, gestores e gestoras de saúde e educação
}

Messages on family and community medicine and primary care directed at family doctors, residents, medical students and health and education managers

Mensajes sobre Medicina Familiar y Comunitaria y Atención Primaria de Salud dirigidos a Médicos y Médicas Familiares, residentes, estudiantes de medicina, gerentes y de salud y educación

\author{
Maria Inez Padula Anderson ${ }^{1}$ (1), Leonardo Cançado Monteiro Savassi',3 (10) (Organizadores) \\ IUniversidade do Estado do Rio de Janeiro, Faculdade de Ciências Médicas - Rio de Janeiro (RJ), Brasil. \\ 2Universidade Federal de Ouro Preto - Ouro Preto (MG), Brasil. \\ ${ }^{3}$ Universidade Aberta do SUS - Ouro Preto (MG), Brasil.
}

No ano comemorativo dos 40 anos da Sociedade Brasileira de Medicina de Família e Comunidade (SBMFC) e dos 45 anos da Medicina de Família e Comunidade (MFC) como especialidade no Brasil, este artigo, na forma de entrevistas, traz mensagens de convidados e convidadas - profissionais que aqui representam a história passada, presente e futura da MFC e da SBMFC. ${ }^{1}$ São profissionais que se relacionam com essa história nestes $40 / 45$ anos, considerando algumas de suas funções na MFC e da SBMFC nesse período. Suas relações com a MFC e a SBMFC podem ser lidas no Editorial desta edição comemorativa. As mensagens sobre a MFC e a Atenção Primária à Saúde (APS) são dirigidas aos e às residentes de MFC, aos e às Médicos e Médicas de Família e Comunidade (MFC), aos médicos e médicas que atuam na APS; aos estudantes de Medicina, aos gestores de saúde e educação e à população geral.

${ }^{1}$ Referências e breve histórico dos autores e autoras podem ser lidos no Editorial.

Como citar: Anderson MIP, Savassi LCM (orgs.). Mensagens sobre a Medicina de Família e Comunidade e a Atenção Primária à Saúde dirigida a Médicas e Médicos de Família e Comunidade, residentes, estudantes de Medicina, gestores e gestoras de saúde e educação. Rev Bras Med Fam Comunidade. 2021;16(Suppl 1):28-32. https://doi.org/10.5712/rbmfc16(Suppl1)3245
Autor correspondente: Maria Inez Padula Anderson

E-mail: inezpadula@gmail.com

Fonte de financiamento:

não se aplica.

Parecer CEP:

não se aplica

Procedência:

encomendado.

Avaliação por pares:

não se aplica

Recebido em: 01/10/2021.

Aprovado em: 17/10/2021.

Editores:

Maria Inez Padula Anderson e Leonardo

Cançado Monteiro Savassi 
RBMFC: Considerando o momento histórico de comemorarmos os 45/40 anos da MFC no Brasil e da SBMFC, deixe uma mensagem para as/os para os especialistas em MFC, para os e as residentes em MFC e para os médicos e médicas que atuam na APS.

Ricardo Donato Rodrigues: A MFC e a APS/Estratégia Saúde da Família (ESF) fortes são o caminho para a consolidação de sistemas de saúde coerentes com a meta "Saúde para Todos". Ser MFC "faz toda a diferença" na vida de pessoas, famílias e comunidades, assim como na saúde ambiental, com especial importância no atual cenário, neste Brasil de tantas iniquidades.

João Werner Falk: O tempo foi me ensinando que é necessário seguirmos sempre trabalhando com qualidade, resiliência, paciência e persistência. Acreditem nos seus sonhos, pois a busca de realizálos faz a diferença nas transformações da realidade em prol da população.

Airton Tetelbom Stein: A carreira de MFC abre muitos horizontes e possibilita, de fato, contribuir para que a sociedade seja mais inclusiva, com menos iniquidade. Houve um desenvolvimento muito grande da especialidade no Brasil.

Maria Inez Padula Anderson: A MFC é uma especialidade complexa, única e apaixonante. Temos o privilégio - e, ao mesmo tempo, a responsabilidade - de advogar pelos serviços à saúde mais adequados e necessários às pessoas, famílias e comunidades, uma vez que somos testemunhas vivas de suas histórias de saúde e adoecimento, no contexto de vida em que ocorrem. Somos testemunhas da qualidade de vida que têm, das condições sociais e econômicas, dos sofrimentos cotidianos, das violências da vida pessoal, em família e em sociedade, do conjunto de fatores que afeta e adoece a quem cuidamos. Por isso, a MFC dá sentido e muda para melhor nossa forma de ser médicas e médicos, muda para melhor nossa visão e a forma de estarmos no mundo. Quem está no caminho da APS e da MFC sabe que a estrada é longa e com obstáculos, mas traz muitas recompensas e compensações. Se fizermos bem nosso trabalho, seguramente estaremos, como aliados terapêuticos, presentes para sempre nas mentes e nos corações de quem cuidamos. Sabemos que não é simples estar e ser MFC no Brasil. É preciso estar consciente de que será preciso resistir e não desistir. E "esperançar", como nos ensina Paulo Freire - o que não é ficar à espera, mas fazer acontecer. O caminho se faz ao caminhar e a utopia não é um ponto cego - ao contrário, é o que nos faz seguir adiante, como já referia Eduardo Galeano. Fortaleçam a SBMFC! E, se você ainda não é, torne-se associada ou associado!

Gustavo Gusso: Melhor acertar por aproximação do que errar com precisão (Kerr White).

Nulvio Lermen: O MFC ocupa um papel de destaque no sistema de saúde. Como um recurso para uma população, ele deve ter a qualidade clínica como seu principal foco, garantindo resolubilidade para seus pacientes. Assim, a MFC como especialidade será cada vez mais valorizada e, consequentemente, vocês também como especialistas na área.

Thiago Trindade: Sejam persistentes na sua missão de cuidar das pessoas. A sociedade em geral só tem a agradecer o trabalho de cada um de vocês, que fazem a diferença para as famílias que atendem. Contem com a SBMFC e as entidades estaduais, busquem sua entidade e se envolvam com o desenvolvimento da nossa especialidade no Brasil.

Daniel Knupp: A MFC é certamente a mais virtuosa das especialidades médicas. É hoje, possivelmente, o principal bastião da ética e dos valores humanistas que vêm sendo perdidos na Medicina em geral. Reconheça-se como MFC, defenda e exerça seus princípios, em qualquer local em que esteja atuando.

Zeliete Zambon: Olhe para você mesmo como uma/um profissional importante do sistema de saúde. Somos os gestores de saúde das pessoas. 
Ana Clara Arantes Gonçalves e Geferson Pelegrini pela Diretoria de Residentes: A MFC enfrenta muitos desafios por trabalhar no contexto da APS mas, apesar deles, vale a pena investir no aperfeiçoamento constante, porque é com uma boa prática da medicina de família que o nível primário da atenção será cada vez mais reconhecido e valorizado.

RBMFC: Considerando o momento histórico de comemorarmos os 45/40 anos da MFC no Brasil e da SBMFC, deixe uma mensagem sobre a MFC e a APS para as/os estudantes de Medicina.

Ricardo Donato Rodrigues: A MFC é uma especialidade apaixonante. Venham nesse embalo, que a aprendizagem nesse campo é fundamental à formação de todo médico.

João Werner Falk: Estudem bastante sobre o que são a MFC e a APS, entendam a importância destas e as valorizem. Participem de ligas acadêmicas de MFC em suas escolas médicas.

Airton Tetelbom Stein: Aqueles que forem realizar essa especialidade devem saber que estarão buscando um SUS cada vez mais forte e também procurarão entender a causa das causas, assim como contribuirão para que tenhamos uma sociedade com menos iniquidade.

Maria Inez Padula Anderson: A MFC é uma especialidade e uma área de conhecimento importantes para todas e todos os estudantes de graduação, mesmo aqueles que não seguirão na especialidade como pós-graduação. Ela amplia nosso entendimento sobre o processo de adoecer, ajuda na adesão medicamentosa, apoia e estimula o vínculo com os pacientes, ao mesmo tempo em que promove a autonomia deles.

Gustavo Gusso: Tentem enfocar os conceitos, estudar as bases e os principais autores como Barbara Starfield e lan McWhinney. Cuidado para não confundirem com a medicina preventiva, que é outra área.

Nulvio Lermen: A MFC é a especialidade que dá a maior oportunidade de atuação em diferentes frentes. O MFC tem sido cada vez mais valorizado na clínica, na docência e na gestão de serviços de saúde. Em qualquer uma dessas frentes, a formação na área será um grande diferencial para seu sucesso profissional.

Thiago Trindade: Acreditem na MFC como uma possibilidade de especialidade. Vocês irão se encantar com o trabalho, sentirão no dia a dia relações fortes de vínculo com seus pacientes. Na graduação, aproveitem seus professores médicos de família para aprenderem e conhecerem nossa especialidade em sua essência. A MFC é uma especialidade do passado, do presente e do futuro. Precisamos de mais pessoas que queiram ser MFC. Essa é uma necessidade do país hoje e sempre.

Daniel Knupp: A MFC é a única especialidade médica que permite o pleno desenvolvimento profissional no âmbito da Medicina. É a essência de ser um(a) médica(o), de poder interagir com as pessoas e com as populações em geral. A prática enquanto MFC é em si uma defesa da equidade e da justiça social. Se esses valores fazem sentido para você, não pense duas vezes na escolha da especialidade.

Zeliete Zambon: Para mim existem quatro disciplinas fundamentais para ser um/uma boa médico/a: bioquímica, anatomia, fisiologia e APS. Se souber essas quatro, poderá ser um bom médico/médica em qualquer especialidade. Ser MFC, implica, além disso, ter outras competências, sendo uma das principais gostar de cuidar de pessoas. A importância da MFC nessa nova medicina será vital.

Ana Clara Arantes Gonçalves e Geferson Pelegrini pela Diretoria de Residentes da SBMFC: Estejam sempre de mente e coração abertos para o que a prática da MFC pode oferecer, porque ela desafia suas habilidades como futuros médicos e pode influenciar a prática de vocês de forma permanente, independentemente da especialidade escolhida que forem seguir. 
Priscila Ferraz Bortolini pela Associação Brasileira de Ligas Acadêmicas de Saúde da Família (ALASF): Existe uma máxima na faculdade de que devemos ser superespecialistas, que devemos focar uma única parte do corpo do paciente e resolver aquele ponto. Ter contato com a MFC na graduação forma um pensamento crítico em relação à sociedade e a nós mesmos. "Que tipo de profissional eu quero ser?" Essa pergunta nos ronda e, quando percebemos que a atenção integral muda a vida de uma pessoa, começamos a enxergar a MFC com outros olhos, o que nos dá ânimo para seguir esse caminho.

RBMFC: Considerando o momento histórico de comemorarmos os 45/40 anos da MFC no Brasil e da SBMFC, deixe uma mensagem sobre a MFC e a APS para os gestores de saúde e educação.

Ricardo Donato Rodrigues: O processo de produção da saúde - a exemplo do que ocorre na educação - é diferente, pois não ocorre sem a efetiva participação de profissionais, das pessoas, de suas famílias e respectivas comunidades. Essa noção é fundamental no tocante à MFC e à APS; transcende cifras e dados quantitativos. Essa complexidade remete a um modelo participativo de gestão que todo gestor deve tratar com sabedoria e carinho muito especial.

João Werner Falk: Informem-se bem sobre o que são a MFC e a APS, mantenham-se atualizados a respeito, conheçam a SBMFC e respeitem os profissionais da APS. Sejam responsáveis na produção de mais saúde para a população.

Airton Tetelbom Stein: A coordenação do atendimento, a integralidade do cuidado e o acesso às demandas mais prioritárias dos pacientes somente serão efetivos e contemplados caso o sistema de saúde - público ou privado - incorpore os MFC no trabalho da linha de frente.

Maria Inez Padula Anderson: Aposte e invista na MFC! Aposte e invista na APS de qualidade! Aposte e invista na ESF! Vocês colherão resultados, mesmo em curto prazo, e serão valorizados por isso. A população saberá reconhecer.

Gustavo Gusso: É fundamental integrar os projetos de APS com a rede existente e criar uma política de atenção secundária (rede referenciada).

Nulvio Lermen: AAPS é a base de qualquer sistema de saúde de sucesso, pois agrega qualidade clínica e custo-efetividade ao sistema. A MFC é a especialidade médica formatada para a atuação na APS e tem o potencial de aumentar o valor agregado de qualquer sistema de saúde.

Thiago Trindade: Apoiem, em todas as instâncias, os processos formativos de médicos de família. Busquem para os seus sistemas de saúde MFC para qualificá-lo. Procurem ampliar o financiamento da APS e tenham como norte oferecer uma APS de qualidade para $100 \%$ de sua população.

Daniel Knupp: Valorize a MFC! A MFC é fundamental para uma APS forte e, consequentemente, para os sistemas de saúde. Só é possível realizar as transformações necessárias no paradigma vigente na saúde a partir da perspectiva trazida pela MFC.

Zeliete Zambon: Você pode até não querer, não dar importância, mas não será capaz de fazer uma boa gestão em saúde sem valorizar a atuação do/da MFC e ter a APS como o principal nível de atenção à saúde.

Ana Clara Arantes Gonçalves e Geferson Pelegrini pela Diretoria de Residentes: Valorizar o trabalho dos MFC e dos residentes de MFC pode parecer um passo atrás em um primeiro momento, quando se pensa apenas em demanda assistencial e se compara com a forma tradicional com que os atendimentos costumam ocorrer quando os profissionais da APS não são especialistas em medicina de família. Mas, em suas localidades, investir na MFC e na APS de qualidade é prover cuidados de saúde que resultarão em uma população com mais saúde e mais autoestima, que receberá sem dúvida o melhor atendimento possível. 
RBMFC: Considerando o momento histórico de comemorarmos os $45 / 40$ anos da MFC no Brasil e da SBMFC, deixe uma mensagem sobre a MFC e a APS para a população.

Ricardo Donato Rodrigues: Saúde é direito de todos. Queira um MFC para chamar de seu.

João Werner Falk: Valorizem o SUS, as Unidades Básicas de Saúde e a ESF e tenham MFC para chamarem de seus.

Airton Tetelbom Stein: Caso você queira viver numa sociedade mais inclusiva, com mais equidade, competência clínica e que valoriza os direitos humanos, exija que o seu prefeito contrate e valorize os MFC.

Maria Inez Padula Anderson: Você já tem um ou uma MFC para chamar de seu/sua? Ainda não? Saiba que nos países que têm os sistemas de saúde mais avançados do mundo, essa especialidade e a atenção primária de qualidade são valorizadas. Você merece ter esse tipo de atenção à saúde. Ajudenos a fazer com que essa especialidade e a APS cresçam e sejam valorizadas no Brasil. A ESF é um modelo de atenção reconhecido e valorizado internacionalmente. É um modelo avançado de APS. Vamos incentivar que os governos municipais busquem a sua implantação e o seu desenvolvimento! E lembre sempre: valorize o SUS! Desconfie de quem quer privatizar a saúde. Saúde não é mercadoria, não se compra e não se vende.

Gustavo Gusso: Vale a pena ter vínculo com profissionais generalistas. Invistam nessa ideia.

Nulvio Lermen: O MFC é o médico que irá acompanhá-lo a cada passo da sua história. Ter a APS como base de um sistema de saúde lhe dará a oportunidade de ter esse profissional ao seu alcance e lhe garantirá maior acesso aos serviços e melhor cuidado de saúde para você, sua família e sua comunidade.

Thiago Trindade: Confiem e defendam a presença de equipes de atenção primária para suas comunidades, com o médico de família compondo essas equipes. É fundamental que as comunidades se envolvam nessa demanda e pressionem seus gestores públicos a ofertar saúde da família de qualidade com a MFC para suas famílias. Tenha um MFC para chamar de seu.

Daniel Knupp: Você já tem um MFC para chamar de seu? Se não, fique atento. Sua saúde pode estar em risco. Sempre busque um MFC de sua confiança para cuidar de você.

Zeliete Zambon: A APS não foi criada para que você não tivesse acesso a saúde, muito pelo contrário. O/a MFC é o profissional que quer estar junto com você para ajudá-lo a fazer a gestão de sua saúde.

Ana Clara Arantes Gonçalves e Geferson Pelegrini pela Diretoria de Residentes: Procure saber qual é o posto de saúde do seu bairro, faça parte do Conselho de Saúde local e lute para que ele tenha um MFC que cuide de você e por um SUS gratuito, universal e de qualidade!

Comentários finais de alguns dos entrevistados:

Ricardo Donato Rodrigues: Agradeço a oportunidade. Senti orgulho de ser consultado. Escutar é uma das virtudes da boa gestão.

Thiago Trindade: Vida longa à MFC!

Zeliete Zambon: A MFC é, junto com a Genética, a especialidade que mais crescerá nos próximos anos e trará a visão de Medicina Personalizada e de Precisão acessível a todos. 